\title{
Taxonomic definitions in social science, with firms, markets and institutions as case studies
}

\author{
GEOFFREY M. HODGSON* \\ Loughborough University London. Stratford, London, UK
}

\begin{abstract}
Definitions are crucial for institutional analysis. This article explains the nature of taxonomic definitions, with particular attention to their use in economics and other social sciences. Taxonomic definitions demarcate one species of entity from another. They are vital for the communication of meaning between scientists, who must share some basic conception of what types of entity they are investigating, to establish a division of labour over subsequent theoretical analysis and empirical investigation of the type of entity defined. Generally, taxonomic definitions build on past usage and are parsimonious: they are not meant to be explanations or descriptions. By contrast, overloaded taxonomic definitions can create square-one disagreement about what is being investigated. As illustrative examples, the paper considers different degrees of progress with attempts to define firms, markets and institutions.
\end{abstract}

\section{Introduction}

The social sciences are plagued with severe and unresolved problems of definition. ${ }^{1}$ Although there will always be some ambiguity and fuzziness, there is a failure in some parts of social science to develop adequate common understandings of terms. Some scholars have argued that definitional tasks should be abandoned. Yet without workable definitions, science can make little progress. Accordingly, when a researcher uses the word 'institution', he or she should be able to point with adequate lucidity to the type of phenomena to which the term is attached.

Among and beyond those that attempt definitions, there is little discussion of their possible nature and requirements. There is little recognition that several different types of definition have been identified in philosophy. It is sometimes

\footnotetext{
*Corresponding author. Email: geoff@vivarais.co.uk

1 The author is very grateful to Ricardo Crespo, Steve Fleetwood, David Gindis, Claudius Gräbner, Francesco Guala, Matthias Klaes, Chris Mantzavinos and anonymous referees for discussions and very helpful comments on earlier drafts of this essay.
} 
suggested that definitions should express everything vital about the phenomenon defined. Such a task would be impossible, and is refuted by examples of effective taxonomic definitions, such as 'a mammal is a clade of animal where the females suckles their young'. This parsimonious but effective definition omits numerous vital features of mammals.

Taxonomic definitions identify the minimum number of properties that are sufficient to demarcate one group of entities from all other entities. Their role is to demarcate the kind of entity to which a label refers, not to express in detail the nature of that kind.

These definitions are established through social practice in varied contexts. Consider a merchant who wishes sell wine inside the European Union (EU). To label the product as 'wine', the merchant must comply with the taxonomic definition of the liquid in EU law. This is 'the product obtained exclusively from the total or partial alcoholic fermentation of fresh grapes, whether or not crushed, or of grape must' (EU Council, 2008). This taxonomic definition does not tell us that the wine is a liquid and it must be drinkable. There is no mention of its possible range of alcoholic strength, or of its culturally significant consumption with meals or in religious rites. These important features of wine are omitted. Yet this taxonomic definition plays the effective demarcatory role of excluding fermentations from other fruits or substances. The practical efficacy of this demarcation is a vital test of a taxonomic definition, and experience can lead to its refinement or revision.

Similar considerations apply in science. Science is a social process, wherein communication and understanding are vital. Scientists need to interact with one another and establish common understandings, including of the terms being used. This transmission of meaning is vital for scientific advance.

Taxonomic definitions are classifications. There is a sociological literature on classification systems that emphasizes their ubiquity in human society. This work shows that classifications are affected by culture, are dynamic, and often affect the (human or material) objects of classification, by determining how we treat them. As Geoffrey Bowker and Susan Leigh Starr (1999: 67) put it in their definitive contribution in this area: 'There is no great divide between folk and scientific classifications.' Maybe so, but science is more than folklore, and we are concerned here with the categories that are used to advance scientific understanding.

For example, investigation of the (true or false) claim that 'capitalism generates inequality' requires an adequate common understanding of what is meant by 'capitalism' and 'inequality'. If there were some dispute over whether or not to include (say) prehistoric trade, ancient Rome, or the former Soviet Union under the category 'capitalist', then attempts to critique or justify the inequality claim would be confounded by major differences over what entities were being 
analysed, thus frustrating the search for possible generic mechanisms that might explain capitalist inequality. ${ }^{2}$

To get anywhere, participants in the dialogue need to establish some minimal common understanding of a term such as 'capitalism', so that inquirers can then identify possible causal mechanisms and place them under some kind of empirical or other scrutiny. This is why taxonomic definitions are important.

Frustration with verbal definitions has been a motive for some social scientists to turn to mathematics. But when mathematics is used, words are still required for the ultimate communication of meanings and understandings (Frigg and Nguyen, 2017; Morgan, 2012). Much scientific communication will always involve ordinary language, with all its trappings and ambiguities.

Definitions in the social sciences are likely to have fuzzy boundaries. But these are not excuses for abandoning the tasks of definition and the vital communication of meaning. Absolute precision, like absolute cleanliness, is impossible; but that does not imply that we should abandon our duties of linguistic housekeeping or personal hygiene.

Scientists must first establish an agreed rough understanding of the phenomena they are investigating. Then they try to focus on the problem, using a taxonomic definition as a means of demarcation. They sometimes change this definition. But definitions matter at every stage. Science is driven in part by a search for meaning.

The importance of adequate definitions has been stressed by a number of leading authors. Thomas Hobbes (1651: ch. 4) warned of the compounded dangers of imprecise definitions. Thomas Robert Malthus (1827) made a systematic attempt to define then-prominent concepts in political economy. He argued that such definitions were different from those in mathematics and set out some rules for their derivation (Machlup, 1963). Today there are numerous attempts, including those in various specialist dictionaries and encyclopaedias, to define key terms in the social sciences. ${ }^{3}$

But the search for absolute precision of basic terms would prevent science getting off the ground. Physics managed to make substantial progress even when the term 'electron' lacked a shared definition (Hacking, 1983). Many other terms remain vague, even in the hard sciences. This has led to defences by philosophers of some 'vagueness' in science (Hyde, 2008; Klaes, 2004, 2006; Russell, 1923).

The focus in this paper is on taxonomic definitions, which have the aim of establishing sufficient agreement on the kind of object of enquiry signalled by a

2 Such wide-ranging inclusions under the category 'capitalism' have been suggested, by McCloskey (2010: 16, 259), Runciman (1983) and Cliff (1955) respectively. See by contrast Hodgson (2015a), where a narrower definition of capitalism is presented. It focuses on well-developed financial institutions and markets, which became dominant in the West no earlier than the 17th century, but were marginalized or absent in Soviet-style economies.

3 For example, Abercrombie et al. (2000), Durlauf and Blume (2008), Jary and Jary (1991), Marshall (1998), Outhwaite and Bottomore (1994), and Williams (1976). 
term. They do not typically provide a further understanding of those phenomena. Matthias Klaes (2006: 21) argued: 'What matters for founding concepts is less that they are well-defined, but that differences over their meaning do not prompt controversy.' The major role of a taxonomic formulation is precisely to minimize controversy over the kind of objects under investigation. A taxonomic definition does not have to be 'well-defined' in the sense that it provides an adequate description, understanding or explanation of the entities involved.

Prominent attacks on definitions and 'definitionism' in philosophy claim that definitions cannot adequately or unambiguously establish the nature of an entity or kind (Fodor, 1998; Fodor et al., 1980; Klaes, 2006). But such a failing does not apply to taxonomic definitions, which do not aim to provide an adequate account of that nature. Their function is different, and they must be assessed in their own terms.

This paper has nine sections. The following section briefly reviews different types of definition and possible attributes of definitions. Taxonomic definitions are considered in the light of these classifications. Section 3 notes that in biology a taxonomic definition may be established by considering branches in the tree of evolutionary descent. But the more tangled processes of evolution of socioeconomic phenomena thwart this approach. Section 4 considers alternative ontological bases for taxonomic definitions. Section 5 discusses further how taxonomic definitions may be established in practice. Sections 6,7 and 8 are case studies of relative failure or success in establishing consensus definitions in social science. The definitions of firm, market and institution are considered respectively. Section 9 concludes the paper.

\section{Taxonomic and other categories of definition}

There are different kinds of definition and different types of object of definition. Furthermore, definitions serve different purposes. For example, a legal redefinition of marriage to include same-sex couples may be motivated by notions of inclusivity or fairness, rather than a concern for scientific categorization. The taxonomic definition of wine in EU law was not constructed to aid scientific investigation, but to regulate trade.

Aristotle (1901: book 2, chs 8-10) distinguished between nominal and real definitions. A real definition involves an explanation of the origin and nature of a type of entity: it is an attempt to outline its essence and function. By contrast, a nominal definition elaborates the meaning of the name that we use.

Clearly, a nominal definition is a necessary condition for attempting a real definition. To attempt to investigate the nature of an object or object denoted by $X$, we must first adopt a view of what class is denoted by $X$. As Carl Hempel (1952:17) pointed out, sciences cannot develop 'without extensive use of nominal definition'. 
But the use of a nominal definition does not imply a rejection of philosophical realism - the view that a (social) world exists that is independent of our mind, beliefs or senses. Nominal and real definitions are different kinds of definition, each compatible with various philosophical outlooks. As Orna Harari (2005: 126) noted: 'From an Aristotelian point of view the ... notion of nominal definition appeals to the essential features of an object.' In other words, nominal definitions can appeal to the realist concept of essence.

The term taxonomic definition is introduced here to denote a mode of nominal definition that addresses not a single entity but a population of entities with some common properties. A population invokes plurality: "There are many "beings" in disjunctive diversity' (Whitehead, 1929: 31). In biology the term population has developed a technical meaning (Mayr 1972, 1982; Sober, 1980). As Peter Godfrey-Smith (2009: 148) explained, 'population thinking' treats 'a system as an ensemble of individual things, which have some degree of autonomy and a significant number of properties in common'.

Populations are commonplace in the social sciences. There are populations of structures, cultures, ideologies, organizations, families, economies, states, individuals and so on. Taxonomic definitions in social science concern populations of social phenomena that exhibit some degree of commonality and some degree of diversity. As in biology, social scientists are forever attempting to classify phenomena in the face of endless diversity and change.

Sciences also contain populations of theories, which are clusters of theoretical approaches with shared characteristics. Examples include postmodernism, neoclassical economics, historical institutionalism and many more. These too are objects of taxonomic definition.

The relatively sparse modern philosophical literature on definitions is dominated by logicians and analytical philosophers. Because taxonomy concerns varied entities, and taxonomies often have problems with fuzzy or unclear boundaries, a classical logical treatment is often problematic. Fuzzy logic may help, but so far it has been little used by logicians in this area (Zadeh, 1996). Consequently, taxonomic definitions are relatively neglected in the philosophical literature. A primary aim of this paper is to help to fill this void by bringing pragmatic considerations into play. ${ }^{4}$

Richard Robinson (1950: 19) distinguished between 'lexical and stipulative definition. Here by "lexical definition" I mean reporting the customary or dictionary meaning of a word, and by "stipulative definition" I mean establishing or announcing one's own meaning for a word' (original emphasis). A lexical definition must simply convey existing meaning, while a nominal definition may involve some stipulation (and some departure from customary or dictionary usages) to establish a more precise meaning of a term.

4 For the pragmatist challenge to analytic philosophy see for example Kitcher (2012). 
This lexical-stipulative distinction refers to the degree to which we may rely on the baggage of meaning that a term may carry in pre-existing discourse. When we invent an entirely new word or phrase to identify a class of entities, we are being entirely stipulative. Alternatively, a stipulative definition may use an already-existing term but stipulate a new meaning.

Many definitions in mathematics have a strongly stipulative character. Such definitions 'must simply be assumed or posited' rather than accomplished through observation (Demoss and Devereux, 1988: 137). For Gottlob Frege (1914), all definitions in mathematics must be treated as purely stipulative.

But outside mathematics, there are problems with purely stipulative definitions. Words (and perhaps even symbols) typically connote prior understandings. It is difficult to get rid of all this baggage of meaning. Science involves rhetorical persuasion in a social community (McCloskey, 1985). The persuasive task becomes more difficult if we ask every reader to expunge all preconceptions and pre-associations, and adopt a number of terms with strikingly novel meanings.

Hence, as Robinson (1950: 80) argued: 'The supreme rule of [definitional] stipulation is surely to stipulate as little as possible' (original emphasis). Similarly, Aristotle wrote in his Topica (1853: II, 2): 'we ought to use our terms to mean the same things as most people mean by them.' Malthus 1827: 4) argued likewise: with terms 'in the common conversation of educated persons, we should define and apply them, so as to agree with the sense in which they are understood in this ordinary use of them'. Malthus insisted that if a new definition is stipulated for an existing term, then its advantages must necessarily be obvious to the reader. Likewise, Alfred Marshall (1920: 43) argued that the terms used in economics should 'conform ... to the familiar terms of everyday life, and so far as possible [economists] must use them as they are commonly used'.

But some contested terms in social science conjure a chaos of contradictory meanings. Consequently, in these circumstances, reliance on lexical appeals is problematic and some stipulation is unavoidable. In practice, given the subject matter and the nature of language, most definitions in social science involve a degree of lexical description and a degree of stipulation. A measure of stipulation is often necessary because words are used in varied and ambiguous ways, and we have to stipulate a more precise meaning. A degree of lexical description is necessary because to be rhetorically effective, and to avoid over-burdening the reader with radically novel stipulations, we are forced to rely on some established meanings.

5 See also Wittgenstein (1958: 20): 'the meaning of a word is its use in the language.' Notably, following most other economists since Adam Smith, Marshall (1920) made an exception to his 'everyday life' rule with his definition of capital in terms of factor inputs rather than the money-related meaning used in business, with possible adverse consequences (Hodgson, 2014). 
Consider another type of definition. An intensional definition establishes the meaning of a term by specifying necessary and sufficient conditions for when the term should be used (Cook, 2009). For example, a triangle is defined as polygon with three straight sides and three vertices. Being a polygon with three straight sides and three vertices is both necessary and sufficient to be a triangle.

By contrast, the term extensional definition is used to refer to the listing of everything that falls under that definition. Hence an extensional definition of bachelor would be a listing of all the unmarried men in the world, including maybe all unmarried men in the past and future! Given the numbers of social phenomena, and the obvious difficulties of listing all types in a class, extensional definitions are often impractical in social science. But some extensional definitions are possible and can be useful. For example, 'sub-Saharan Africa' may be defined simply by listing the 49 countries that are generally taken to fall into this category. This performs a similar (but not identical) taxonomic function to defining sub-Saharan Africa as 'the area of the African continent that lies south of the Sahara'.

But taxonomic definitions do not fit easily into the intensional-extensional dichotomy. Typically, they are not extensional. They are closer to being intensional, but they provide merely sufficient criteria to demarcate one species from another.

To take stock of these issues, we consider that taxonomic definitions in social science:

1. are generally nominal, rather than real in the sense used by Aristotle (but this does not imply a rejection of philosophical realism),

2. are generally not intensional in the full sense of providing necessary and sufficient properties to communicate the nature of an entity or type,

3. may be extensional but more frequently, for practical and other reasons, they are not,

4. are often lexical to a large degree, and

5. typically involve a lower degree of stipulation than that found in mathematics.

In addition:

6. The purpose of taxonomic definitions is to establish sufficient shared meaning, so that a class of entity can be investigated by a scientific community.

7. Taxonomic definition is not the same as an adequate description, explanation or analysis of a class of types.

8. Some consensus on taxonomic classification is prior to such investigations, but the taxonomic definition may be adjusted in the light of new understandings as they emerge.

\section{Taxonomic definitions and evolutionary descent}

Having addressed their character, we now consider how taxonomic definitions are established. Here social scientists can learn from biology, but there are 
important differences. Biology and the social sciences share the basic problem of classifying species or types within a world of change and immense variety (de Queiroz, 1994). It is often difficult to draw boundaries. But in at least one important respect, the difficulties of definition and classification in the social sphere are even greater than in biology. This is due to important differences in the evolutionary processes involved in the two spheres.

Biology establishes taxonomic definitions with reference to evolutionary descent from a common ancestor. The existence of a shared common ancestor is the necessary criterion for establishing a taxonomic class. Then all descendant forms, notwithstanding their variation, are placed in the same category.

The ancestral lineage is traced from an approximate point where a distinctive change or mutation occurs, so that later descendants are identifiably different from earlier ancestors. Some distinctive features appear and then persist among descendants, despite the ongoing generation of variation and tree-like divergence.

Hence taxonomy in biology can be accomplished by focusing on a few key properties. Consider the taxonomic definition of a mammal, noted above. There are strange boundary cases, such as the duck-billed platypus, which suckles its young but also lays eggs. But the suckling criterion has been sufficient to demarcate the whole clade - including marsupials, mice, mammoths, walruses and whales - from other living things, including reptiles, birds and insects.

This suckling definition does not attempt to describe mammals in more detail, or to list a host of important common properties. It omits crucial descriptive characteristics, such as being warm-blooded vertebrates with four limbs, or having lungs and brains. The suckling criterion is sufficient to demarcate, and hence it can serve as a taxonomic definition. In general, taxonomic definitions are neither explanations nor adequate descriptions of classes of entities. ${ }^{6}$

In biology the formulation of definitional demarcation criteria are facilitated because the evolution of species is hierarchical or tree-like: when a new species emerges it diverges from the others, and its members rarely inter-breed across species boundaries (at least with the capability to produce offspring). Hence it is typically sufficient to identify distinguishing, characteristic properties that emerge at the base of a branch of the tree of evolutionary descent. ${ }^{7}$

6 To illustrate the way in which taxonomic definitions can be updated, note that the mammal clade has been recently defined in a different way, involving jaws and teeth rather than the suckling of infants. The leading palaeontologist Tom S. Kemp (2005: 3) defined mammals as 'synapsids that possess a dentarysquamosal jaw articulation and occlusion between upper and lower molars with a transverse component to the movement'. In Kemp's view, this criterion is sufficient to identify the clade originating with the last common ancestor of both Sinoconodon (an early type of mammal found as fossils in China) and more recent mammals. This shift of definition is tied to the need to classify fossils, where mammary glands and other soft tissue may not have survived. The increasing importance of fossil evidence has led to a new taxonomic definition.

7 By prominent accounts, the limits of a species are defined in terms of the possibility, or otherwise, of inter-breeding (de Queiroz, 2005). 
In biology, some hybridization is possible but limited. Hence the hierarchical, tree-like picture of evolutionary descent is largely preserved. By contrast, in the social sphere, hybridization and the replication of hybrids is commonplace. For example, the English language is a fusion of multiple language types, with Latin, Germanic and other roots. Some prominent legal systems involve combinations of common and civil law. While some component capitalist institutions (such as property and markets) may have evolved independently in different locations, we know that global interactions and institutional borrowings played a major part in the emergence and evolution of individual capitalist systems (Hodgson, 2015a). Institutions that develop in one country or setting are frequently copied and installed in another. Social evolution widely involves reticulate (with divergence and much recombination) rather than hierarchic (involving divergence but with minimal recombination) patterns of descent.

Consequently, most species of social phenomena cannot be conceptualized in terms of a single, earliest, common ancestor, from which all others in tree-like formation descend. It is mostly ineffective to follow biology and identify a few novel features shared by that earliest ancestor and its descendants, and then use these properties as the definitional criteria. While phylogenetic methods of classification are often applied to languages and other social phenomena, they become less effective when there is greater reticulation or recombination.

\section{Realist versus nominalist ontological grounds for taxonomic definitions}

Because they cannot rely on shared evolutionary descent to perform the classification, social scientists must look to other grounds for taxonomic definitions. This opens up a philosophical can of worms. The old philosophical contest between nominal and realist ontologies becomes relevant. Nominalism denies the existence of universals. But the realist-nominalist ontological dilemma is different from the real-nominal dichotomy concerning types of definition. Aristotle addressed both real and nominal definitions, but from the perspective of a realist ontology that accepted universals.

By contrast, from a nominalist ontological perspective, all taxonomic definitions must be regarded as categorizations of convenience that we impose upon collections of entities. The warrant for any particular taxonomic classification is that it proves useful for analysis. But this creates a definitional catch-22. Proposers of definitions must do much analytical and empirical work before they can claim some warrant for the definition that is proposed. Yet science requires an analytical and empirical division of labour, and some prior consensus must be reached on definitions among the researchers involved before the analytical and empirical work yields some fruit.

A realist ontological approach does not dispense with such difficulties, but it offers an additional grounding for taxonomic proposals. As Plato reported of Socrates in Phaedrus, the approach is to 'carve' reality 'where the joint is'. 
This raises the contested Aristotelean concept of essence. Aristotle distinguished between essential and accidental (or incidental) properties of a kind. As John O’Neill 1998: 8) put it: 'The essential properties of an entity of a particular kind are those properties of the object that it must have if it is to be an object of that kind. ${ }^{18}$ By contrast, an accidental property is one that may be found in the population of that type, but is not universal for that type. For example, some humans are characterized by properties that other humans do not possess - such as blue eyes - so they are 'accidental'.'

As Aristotle explained in his Metaphysics (Aristotle, 1956), the essence of what an entity is cannot be adequately defined in terms of what an entity does, including by the patterns that it generates. If we make this confusion, then we wrongly imply that when the entity interrupts its characteristic activity, then it ceases to be such an entity. Sometimes birds fly. But what helps define a bird is the (existing or ancestral) capacity to fly, not flying itself. If a bird were defined as a flying animal, then any bird sitting on a branch or pecking on the ground would cease to be a bird. If a firm were defined as an organization producing goods or services, then when the workers were on holiday the firm would cease to exist. It would be better to define a firm as an organization with the capacity to produce goods or services. The substitution of transient behaviours for dispositions or capacities is one of the major methodological mistakes in the social sciences.

Definitions or ontologies that are based principally on behaviour cannot cope with instances where the behaviour radically changes or ceases. But the capacity to produce the original characteristic behaviour may endure. Although ancient, this point is not arcane; it is widely utilized in modern realist philosophy of science (Bhaskar, 1975; Harré and Madden, 1975; Lawson, 1997; Popper, 1990).

From an Aristotelian perspective, the task is to identify a minimum number of essential properties that can substantiate a taxonomic definition. These particular essential properties are chosen for their taxonomic effectiveness, not for (say) descriptive adequacy or causal relevance. Taxonomic definitions are not meant to be adequate accounts of the essence. Their role is to demarcate, not to describe adequately or to analyse. An ontological realist would argue, because of reticulate rather than hierarchic evolutionary descent, taxonomic definition in the social sciences should refer to essences and choose key elements from those properties. ${ }^{10}$

8 The word essential is ambiguous. It can refer to something that is part of the essence of a kind, or to something that is vital to its existence. Here essential refers to part of the essence of a type. Hence, for the purposes of definition, listing the 'essential properties of an entity' does not mean listing all the things that are vital for its survival.

9 Quine (1960) argued that it was generally difficult and often impossible to disentangle essential from accidental attributes. See also Robinson (1950: 154-156). But Rasmussen (1984) pointed out that Quine had shifted the discussion of essences from Aristotle's species or kinds to a single individual. When we address species or kinds the distinction between essential and accidental properties becomes clear.

10 While Aristotle's writing does not seem to be entirely consistent, Demoss and Devereux (1988: 148) cited passages that imply that nominal definitions (of which taxonomic definitions are one type) must 
But Aristotle made a problematic additional assumption, which is relevant to the treatment of populations. He generally presumed that variations among species were temporary deviations from one characteristic form. Accordingly, an Aristotelean definition could appeal to a belief that all varieties were gravitating to one 'natural' type. Elliott Sober (1980) described this as the 'natural state model'.

Sober further argued that one of Darwin's underpinning philosophical achievements was to abandon the natural state model. His 'population thinking' upgraded the treatment of variations from awkward deviations to drivers of evolutionary selection and change (Mayr, 1972, 1982). But the problem remains that while biologists can appeal to common evolutionary descent for their classifications of populations, this device is much impaired in the social sciences, for reasons given above.

Nevertheless, discussions of (say) enduring varieties of business firms within industries (Nelson, 1991), or of persistent varieties of capitalism (Hall and Soskice, 2001), can be interpreted in terms of the abandonment of the natural state model and the adoption of population thinking (Hodgson, 2016).

Clearly relevant here is the philosophical literature on kinds. ${ }^{11}$ Taxonomy involves the identification of a genus or kind. The same nominalist-realist ontological dilemma remains. Is the world already sorted into kinds and is it our job to identify and label them? Or, at the other extreme, are kinds simply categorizations of convenience that we impose upon otherwise-unstructured observations?

It is possible that classifications themselves will alter the phenomena being classified. This is sometimes described as reflexivity. In such circumstances Ian Hacking (1995: 370) wrote: 'There is a looping or feedback effect involving the introduction of classifications of people.' Hacking (1999) referred to 'interactive kinds' within a 'dynamic nominalism'. ${ }^{12}$

Richard Boyd (1991) attempted to cope with the problems of fuzziness, mutability and reflexivity with his notion of 'homeostatic property cluster kinds'. Properties of a kind are clustered because they come in an interconnected package, where shared causal mechanisms engender and help stabilize some similarity. ${ }^{13}$ Accordingly, Boyd defended the idea that kinds are real, and not simply arbitrary conventions of a linguistic community. Amie L. Thomasson

involve essential properties: 'an account which mentions merely incidental properties of a thing could not be a nominal definition since it is not an account of what that thing is.'

11 John Locke (1690) and John Stuart Mill (1843) were key contributors (Boyd, 1991; Magnus, 2015).

12 Hacking $(1995,1999)$ originally suggested that interactive kinds were absent from the natural world. But Douglas (1986) had already pointed out that interactive kinds are found in nature too. Hacking (2007) changed his view and became doubtful concerning the notion of kinds.

13 Aristotle's 'natural state model' (Sober, 1980) suggests stronger mechanisms of convergence than those proposed by Boyd (1991). Boyd's view seems consistent with a realist and post-Darwinian view 
(2003) developed the notion of 'institutional kind', where interactions between beliefs and social reality are also taken into account.

Given all this, whether from a nominalist or realist ontological perspective, taxonomic definitions identify the minimum number of properties that are sufficient to demarcate one group of entities from all other entities. This applies to taxonomic definitions in both biology and social science, but evolutionary biology often offers short cuts, via phylogenetic hierarchic descent, that are often absent in social science.

From a realist ontological viewpoint, the usefulness and persuasiveness of a taxonomic definition depends in part on whether it points to a subset of distinguishing properties of a common essence among a population of entities. They may have a similar causal origins that are worthy of investigation, or they have correlated properties that support generalizations, even if they do not share a common ancestry. By contrast, ontological nominalists appeal primarily to analytical utility and the demonstrated capacity for scientific progress. But in both cases the proof of the pudding is in the eating.

\section{More on the pragmatics of taxonomic definitions}

From whatever perspective, taxonomic definitions should be parsimonious. The efficiency of communication is improved by judicious parsimony, which can help to form a scientific consensus upon the basic meaning of a term. Parsimony impels us to establish a minimal list of definitional properties with maximal effectiveness. Taxonomic definition of a kind cannot include everything that is vital for the existence of that kind. Such an impractical definition would consist of an unending list of everything required for the entities to function. Furthermore, the over-extension of the list of definitional properties can spur disagreement and impair communication. A definition 'should be empty of assertional content beyond its ability to explain meaning' (Belnap, 1993: 122).

We must seek some precision with words, to help us dissect a messy reality with sharp concepts of the mind. Taxonomic definitions point to specific identifying features: they are not just descriptive lists of attributes. The definer has also to persuade others that the identification of a particular class of entities (even if well understood) would point to useful, further theoretical and empirical exploration.

After establishing a taxonomic definition, analysts then have the big job of understanding the origin, nature, structure, composition, survival, operations and functions of this type of entity. This larger task is likely to be advanced further using a division of labour in a scientific community. The taxonomic definition is a necessary preliminary step for science - to ensure that multiple analysts are talking about the same thing. Although taxonomic definitions are

of kinds (or species) without Aristotle's insistence that all variations are aberrations from one form (Hodgson, 2016). 
affected and updated by ongoing analysis, definition and analysis are different tasks.

Hence a taxonomic definition of (say) capitalism is not a theoretical analysis of capitalism. Also a taxonomic definition of capitalism is not a list of characteristics that are vital for capitalism to exist. A taxonomic definition may seem simple, but it is not a simplifying assumption. It does not give us licence to ignore in analysis important properties that do not appear in the definition.

The kind of definition we require involves a minimal list of characteristics that can differentiate (say) capitalism from other social formations. Its primary purpose is to ensure that researchers can communicate their meaning effectively when using a category such as capitalism. They may not agree on a single definition, but it is vital to understand what a researcher means by the term when he or she uses it. This preliminary understanding is necessary before the researchers try to explain the emergence or functioning of the kind of entity involved.

The art of taxonomic definition pays attention to the empirical reality where populations are found and to the previous usages of the terms used to describe those species. Although formal models may be heuristically useful, they may over-infuse the process with elements of stipulation that are more suited to mathematics than taxonomy, and they may divert attention from the vital empirical material. Taxonomic definitions that derive principally from mathematical models are often suspect.

Before we move on to some case studies, it will be useful to compare the idea of a taxonomic definition with Max Weber's concept of an ideal type. In a 1904 essay, Weber (1949: 107) argued that conceptual precision was required not despite but because of the changing, tangled and complex nature of socio-economic reality: 'it is because the content of historical concepts is necessarily subject to change that they must be formulated precisely and clearly on all occasions.' Accordingly, real-world muddle was no excuse for a muddled conceptual model. Clear, fixed concepts were necessary to deal with even a messy and changing reality. Similar observations apply to taxonomic definitions.

Weberian ideal types must entail basic definitional classifications, but they amount to much more than taxonomic definitions. They are fuller theoretical constructions, built for the task of 'revealing concrete causal phenomena in their interdependence, their causal conditions and their significance' (Weber, 1949: 92). Ideal types aid theory construction, after the task of taxonomic demarcation. The ultimate fruitfulness of an ideal type must depend on its success in locating and revealing significant causal linkages in the phenomenon under investigation. This is way beyond the task of taxonomic definition, although it depends upon it. Taxonomic definitions are vital to identify a type. But when that type is identified it is necessary to examine how entities are causally constituted and how they interact. 
While ideal types and a taxonomic definitions are different, they both have some fixity in the face of potentially turbulent complexity. Taxonomic definitions and ideal types both must be as distinct as possible, despite the messiness and turbulence of social reality. ${ }^{14}$

\section{First example: defining firms}

From about 1945 to 1990, the theory of the firm was a burgeoning and exciting area of research in economics. After a debate on how the goals of the firm should be modelled (Machlup, 1967), theorists began to look more at the firm's structure and try to explain its nature and performance (Alchian and Demsetz, 1972; Cheung, 1983; Fama, 1980; Hart and Moore, 1990; Jensen and Meckling, 1976; Williamson, 1975). But progress slowed and there has been relatively little theoretical development in this area since $2000 .{ }^{15}$

A major problem is that economists cannot agree what a firm is. Different arguments for the existence and productivity of the firm often cannot readily be tested conjointly, partly because of a lack of clear definitions. The institutional economist Thráinn Eggertsson (1990: 158) noted that the lack of standardized vocabulary and careful definitions made it 'difficult to see whether we are dealing with overlapping or competing theories'. This is a chronic problem with empirical work on the theory of the firm (Carter and Hodgson, 2006).

Leading economists argued that a definition should not even be attempted. Fritz Machlup (1967: 26) listed no less than ten 'concepts of the firm employed in the literature of business and economics', and suggested that even more were in use. He argued that the firm had been regarded as an organization, a decisionmaking system, a collection of assets and liabilities, a juridical person, a business unit under a single management, and much more besides. Machlup (1967: 28) then concluded:

This exercise should have succeeded in showing how ludicrous the efforts of some writers are to attempt one definition of the firm in economic analysis ... I hope that there will be no argument about which concept of the firm is the most important or the most useful. Since they serve different purposes, such an argument would be pointless.

But this is a non sequitur. The proposition that several different 'concepts of the firm' exist does not imply that the formulation and promotion of one best definition should be abandoned. On the contrary, it could be argued that the very confusion itself calls out for a single, commonly accepted taxonomic

14 For critical discussions of Weberian ideal types see Commons (1934), Hindess (1977), Machlup (1978) and Hodgson (2001).

15 Among the foremost 20 results from a Google Scholar search using 'theory of the firm' (performed 28 May 2017), only four items were from 2000 or later. Only one of these four was from a leading mainstream journal of economics. 
definition. Machlup rightly pointed out that these different concepts 'serve different purposes'. But it did not occur to him that these different definitions might also point to different things. A (legal) firm is not the same thing as a business unit, or a collection of assets, or a production plant. These are not simply different concepts: they are different entities. Accordingly, we require a plurality of concepts to refer to a plurality of real arrangements. Machlup was more aware than many economists of the philosophical issues entailed in conceptual exegesis, but he made little acknowledgement of the nature and role of different kinds of definition and their importance for scientific progress.

Steven Cheung (1983: 17-18) argued that any definition of the firm is subjective and arbitrary: 'according to one's view a "firm" may be as small as a relationship between two input owners or, if the chain of contracts is allowed to spread, as big as the whole economy.' He then concluded: 'Thus it is futile to press the issue of what is or is not a firm.' Cheung's argument was basically this: because different definitions of $X$ are possible, it is futile to define $X$. But this too is a non sequitur. If different taxonomic definitions exist, then to communicate we have to make clear the one we have chosen rather than abandon definitions altogether. Cheung showed no appreciation of the fact that shared taxonomic definitions are vital for scientific communication and development. His subjective and arbitrary view of definition is inconsistent with an understanding of science as a social process, requiring conceptual demarcations and shared understandings of terms.

Other researchers point to new organizational firms, new organizational structures, business networks, extended outsourcing, and so on, and then suggest that defining the firm is misconceived because of the new reality. But as Weber (1949: 106-107) argued, the messiness or changeability of reality makes conceptual precision all the more vital. To understand variety or change, we need clear reference points.

One taxonomic category - the firm - is obviously insufficient. We need additional concepts such as business unit, production plant and conglomerate to describe other important structures in the business world. Multiple concepts are required to describe multiple types of entity. But we still need taxonomic categories to help define what we are talking about.

There is a related controversy about what are described as firm-market hybrids. Assuming such hybrids exist, we would still need some definition of firm and market to understand them.

But because no consensus definition of the firm was established, its identity began to slip away. Oliver Williamson (1991: 271) saw hierarchies (or firms) as 'a continuation of market relations by other means'. Instead of the firmmarket dichotomy (as in Coase, 1937), Williamson eventually adopted a firm-market continuum, wherein the firm became a mutation of the market. Richard Langlois (1995: 72) observed that research in this area 'has reached the conclusion that the distinction between firm and market is little more than 
semantics'. It seemed that the firm had lost its identity: it could be treated as an extended market.

We may speculate that one reason why innovative research into 'the theory of the firm' has slowed down dramatically may be this failure to establish a shared taxonomic definition of the central object of analysis. The term firm is still in widespread use - to refer vaguely to some site where production takes place but there is no consensus on its meaning or boundaries. This is an example of the failure of taxonomic definition, and of some of the possible consequences. ${ }^{16}$

\section{Second example: defining markets}

This next case study is not about a refusal or failure to define, but it concerns arguments for a single particular definition among others. Definitions generally vary in their broadness and historical specificity, and conceptions of the market are no different in this regard. The primary problem here is not the rebuttal of definition in principle, but a failure to agree on the broadness or narrowness of the taxonomic category.

Some choose to define markets very broadly. Ludwig von Mises (1949: 257) defined the market economy as 'the social system of the division of labour under private ownership of the means of production'. Here the historical boundaries of the market depend on what is meant by 'private ownership'. He defined ownership in terms of control of the services that derive from a good, rather than in terms of legal rights. Mises (1949: 97) saw all action, even by an isolated individual, as 'exchange' - as an attempt to swap inferior for superior circumstances. Hence private ownership and exchange could apply to most of human history and even to solitary actors that do not contract with others. This extremely broad conception of the market embraced all voluntary transfers or transformations of assets.

But this extremely inclusive definition undermined Mises' normative arguments about the superiority of markets. If markets characterize most of human existence, then arguments in their favour have less significance and leverage (Rosenbaum, 2000).

A narrower taxonomic definition of market might emanate from a narrower conception of exchange, which relied on something resembling enforceable contracts. The market would then be synonymous with trade in general. Trading in commodities has been going on for tens of thousands of years.

16 It is beyond the scope of this essay to try to fill the void and establish a viable definition of the firm. But it has been suggested that criteria concerning legal personality or agency could be used to delineate firms from non-firms (Deakin et al., 2017; Gindis, 2009, 2016; Hodgson, 2015a). This approach confines the firm to spheres where meaningful and effective legal systems are in operation. This is a narrow definition, but not as narrow as some others. For example, Coase's (1937) classic (but later abandoned) definition of the firm in terms of employment relations excluded worker-owned cooperatives and single-person enterprises. 
A further definitional narrowing is possible. Should the market be regarded as coextensive with the contractual exchange of goods or services per se, or given an even narrower meaning and used to refer to forms of organized, recurrent exchange activity? Minimization of stipulation requires a definition of a market that is close to its everyday (lexical) meaning - a place with regular, organized exchanges of goods or services. This suggests a narrow definition, with a relatively sharp historical, institutional and analytical focus.

A market originally referred to a specific place where people gathered and exchanges of particular kinds of commodity occurred. The markets in China in about $3000 \mathrm{BC}$ and in Athens and the Middle East in the sixth century BC involved recurrent trade organized in specific locations (Hodgson, 2015a). Originally permitted by royal charters, medieval markets in England and elsewhere were located and regulated in specific towns. There are also permanent buildings that function as 'markets' or 'exchanges' for agricultural products, minerals, financial stocks and so on. Although today it has acquired additional meanings, the term 'market' still refers to places where trade is organized.

It is on narrowly defined markets, with repeated trades in goods or services of a similar type, that price signals become more meaningful. The operation of the law of one price (where similar items at similar times and locations have similar prices) is sometimes taken as an indication of the existence of a market. The organized competition of the market and its associated information facilities are necessary institutional conditions for any gravitation by similar items to a similar price level.

The narrow definition usefully distinguishes between forms of trade that do and do not take place in markets. Many real-world commercial transactions do not take place in competitive market arenas (Dore, 1983; Goldberg, 1980; Richardson, 1972). Instead firms are involved in ongoing and more intensive bilateral relationships: the parties cooperate and exchange relevant information before or after the contract itself. This is often described as 'relational exchange' or 'relational contracting'. It is very different from the more impersonal and competitive exchanges found in organized markets.

Modern electronic communication makes it possible to organize markets that are unconfined by any physical location. Bidders can communicate with other traders and the market organizers over long distances, as well as with many financial markets. The market-place can disappear, as in the case of Internetbased markets such as eBay. These are markets, even by a narrow definition, because they involve ongoing, high-volume trade and are subject to organized procedures and rules.

The market may be defined narrowly in the following taxonomic terms: a market is an institution through which multiple buyers or multiple sellers recurrently exchange rights to a substantial number of similar goods or services of a particular type. Markets involve multiple exchanges, with multiple buyers or multiple sellers, and thereby a degree of competition. Markets involve 
legal and other rules that help structure, organize and legitimize exchange transactions. Markets, in short, are organized and institutionalized recurrent exchange. According to this narrow definition, not all trade takes place on markets.

But it is often difficult to draw the line between organized and relational exchange, with many possible intermediate cases. Such definitional difficulties are typical when dealing with highly varied phenomena. But the difficulty of defining a species does not mean that the species should be undefined. The boundaries of the class of market entities are fuzzy. We may even wish to consider 'degrees of marketness' (Block, 1990; Rosenbaum, 2000).

Even if we choose a broader definition, there are phenomena that we should avoid describing as markets. For example, following Aaron Director (1964), Ronald Coase (1974) and Coase and Ning Wang, 2012: 190-207) advocated a 'market for ideas'. Does this literally mean that full property rights in ideas should be established (as with goods) and that ideas should all become priced and traded on a market? Not so. We have ideas, but we do not necessarily own them in a legal sense. Coase and Wang referred principally to the need for 'freedom of speech and expression' and for 'the creation and transmission of knowledge' through educational institutions. By misleadingly describing all this as a 'market', Coase devalued his insistence elsewhere on the importance of property, and on the non-universality of the price mechanism.

Nevertheless, substantial work in economics and sociology has focused on real-work markets and examined their relations and dynamics. ${ }^{17}$

\section{Third example: defining institutions}

The third case study concerns a term where there is a near-consensus over its definition. The above discussion of taxonomic definitions defuses attempts to disturb this emerging consensus.

The depiction of institutions as socially operative (rather than merely declared) systems of rules is prominent in the literature on the topic. ${ }^{18}$ But some issues remain that require clarification. And there are some rival definitions, notably where institutions are regarded as equilibria, particularly in terms of game theory (Aoki, 2001; Binmore, 1994, 1998; Lewis, 1969).

Frank Hindriks and Francesco Guala (Guala, 2016; Hindriks and Guala, 2015 ) attempted to synthesize the rule-based and equilibrium-based conceptions.

17 For a selection see Baker (1984), Härdle and Kirman (1995), McMillan (2002) and Mirowski (2007).

18 See for example Rowe (1989), North (1990), Ostrom (1990), Knight (1992), Crawford and Ostrom (1995) and Mantzavinos (2001). But Mantzavinos (2006) argued that disputes over definitions of terms like institution fall into an 'essentialist trap', and that researchers should concentrate more on explanations. However, contrary to Mantzavinos, the adoption of nominalist definitions rebuts neither ontological realism nor essentialism. 
They develop a 'rules in equilibrium' approach. Their principal argument against the exclusively rule-based approach is that it does not explain why rules are followed, or why they remain stable.

But it is not the task of a taxonomic definition to explain why things work, or even to signal the type of explanation that would be required. The work of Guala and Hindriks is more concerned with understanding the general nature of institutions, rather than defining them in a taxonomic sense (Hodgson, 2015b). As the definition of a mammal illustrates, taxonomic definitions should be as parsimonious as possible, while retaining effective demarcation criteria. The addition of the equilibrium concept may be important for explanatory purposes but it is unnecessary for a taxonomic definition. ${ }^{19}$

Hindriks and Guala make an important contribution to the debate about the nature of institutions. But for the primary taxonomic purpose of agreeing on what the debate is about, the 'systems of rules' definition is adequate. Adding additional clauses such as 'in equilibrium' to the taxonomic definition would create more controversy than is necessary at the primary stage. After common agreement on the object of analysis, their important argument about how rules are sustained and enforced comes into play.

The rule-based definition is still effective and meaningful in demarcatory terms. For example, social theorists typically define social structures as sets of relations between individuals (Porpora, 1987). Consequently, all institutions are social structures, but not all social structures are institutions. For example, the demographic or gender structure of a society is part of its social structure; but they are not necessarily systems of rules, and hence they are not institutions. The 'systems of rules' definition of an institution does the job of excluding these important non-institutional phenomena: it is an effective demarcation device.

Hindriks and Guala rightly point out that rules must be more than mere declarations to serve as the constituent elements of institutions. But this issue can be addressed in the definition and analysis of the rule itself (Crawford and Ostrom, 1995; Epstein, 2015; Searle, 1995, 2005). Ludwig Wittgenstein (1958) emphasized 'that what constitutes a rule is our collective use of $i$; rule-following is a general practice established by agreement, custom, and training' (Grayling, 1988: 80). The definition and nature of a rule are vital additional questions, and not necessarily part of the taxonomic definition of an institution that refers to rules.

19 It is also possible to question the use of the equilibrium concept in explanatory terms. For example, if an institution is briefly destabilized, such as during a revolution leading to a change of monarch, then that does not necessarily mean that the institution of monarchy ceases to exist. Note also that in uses of game theory to analyse institutions (Schotter, 1981; Binmore, 1994, 1998, Aoki, 2001) the resulting game equilibria themselves establish rules. For example, with the coordination game of driving-on-the-left versus driving-on-the-right, the two possible equilibria are both (regulative) rules. 
The rules that constitute institutions include norms of behaviour and social conventions as well as legal rules. ${ }^{20}$ Accordingly, systems of language, money, law, weights and measures, traffic conventions, table manners and organizations are institutions. But not all institutions are organizations. For example, language is an institution but not an organization.

Some have expressed uneasiness with this broad taxonomic definition of institution, which includes so many different things, from languages to political structures. Are such capacious definitions flawed? If so, the definitions of a mammal, an animal or a tree might also have to be rejected as overly capacious. On the contrary, instead of a rejection of the primary classification, capacious outcomes point to the need for subclassification and further differentiation.

Consider another problem. It is widely accepted by leading scholars (Giddens, 1984; Guala, 2016; Miller, 2010; Parsons, 1983; Scott, 1995) that organizations are a special form of institution. Despite this, North is often attributed with a definition of institutions that excludes organizations. In key passages that are cited in support of this claim, North (1990: 3-5; 1994: 361) did not make it sufficiently clear whether he was defining organizations as players or treating organizations as players as an analytic abstraction. This has created much confusion, with some of his readers insisting that organizations should be defined as players.

But in personal correspondence - reproduced in Hodgson (2006) - North indicated that he treated organizations as players for the purpose of macroanalysis of the socio-economic system as a whole, and that he did not regard organizations as the same thing as players in all circumstances. ${ }^{21}$ In saying that 'organizations are players', North was making an abstraction for particular analytic purposes, rather than defining organizations in this way. The scarcity of discussion in social science about the nature and role of definitions has contributed to this confusion.

An organization may be defined as a special type institution that also involves (1) criteria to establish its boundaries and to distinguish members from nonmembers, (2) principles of sovereignty concerning who is in charge and (3) a structure delineating responsibilities within the organization. These conditions

20 The ambiguous terminology of formal versus informal institutions is often deployed but much less often defined. Sometimes 'formal' is intended to mean codified. Others use it to mean designed. Still others use it to refer to laws. Given this confusion, the intended meaning of these terms should always be clarified.

21 North et al. (2009: 15) seemed to contradict this. They wrote: 'In contrast to institutions, organizations consist of specific groups of individuals pursuing a mix of common and individual goals through partially coordinated behavior.' If they had put 'In contrast to other institutions, organizations ...' then the contradiction would have disappeared. But then North et al. 2009: 16) went on to say that 'most organizations have their own internal institutional structure', which confusingly suggested that most organizations contain institutions. Incidentally it is misleading to define organizations as 'specific groups of individuals' because individuals often leave or enter organizations without organizations changing their identity (Epstein, 2015). 
imply the existence of social roles or positions that have properties irreducible to those who occupy them.

\section{Conclusion}

The aim of this paper has been to reinforce our understanding of the nature and importance of taxonomic definitions in social science. There are several different types of definition, and among them taxonomic definitions play a vital role. They are relevant in regard to particular real-world (ontological) circumstances, where scientists necessarily operate within epistemic communities involving communication and shared understandings (Kitcher, 1993).

From a realist ontological perspective, the circumstances to which taxonomic definitions apply involve populations of entities of one type or species, which vary among themselves in important respects, but retain some essential properties in common. Such populations or species are found in both the social and biotic worlds. Classificatory problems, emanating from fuzzy boundaries and changes in populations through time, are ubiquitous.

In biology, taxonomic definitions can sometimes rely on the tree-like descent and division of species. But in the social sciences, because of rampant hybridization and reticulate patterns of descent, this device is generally ruled out. It is suggested above that the Aristotelean notion of essence can be useful in such difficult circumstances to help devise taxonomic definitions. These then become a minimal list of definitional properties that can serve to differentiate one kind of entity from another.

Whether we take a realist view that taxonomic definitions somehow relate to essences, or a nominalist view that they are no more than instruments of thought, taxonomic definitions are crucial for empirical and theoretical enquiry. They are vital for communication between scientists as primary devices to establish a shared understanding of what objects of analysis are being addressed.

Although further analysis may lead scientists to alter their basic definitions (as well as the more routine tasks of subclassification) taxonomic definition and analysis are different tasks, but some progress with the former is always a precondition of the latter. Because of the need to communicate, and to minimize dispute over basic ideas that are necessary for scientific cooperation, taxonomic definitions should be parsimonious.

Three case studies illustrate different sorts of problems in this area. They highlight different degrees of consensus on workable taxonomic definitions. But these problems are not confined to these cases. Unfortunately they are widespread.

The first case study highlights a failure to establish a shared taxonomic definition of a firm, alongside influential but misguided warnings that such a definition should not even be attempted. This hiatus may have prevented the crucial formation of consensus over meaning and impaired further development 
after an illuminating outburst of energy and conjecture that had ebbed away by the year 2000 .

The second case involves a range of taxonomic alternatives, in this instance over the meaning of the term market. A case is made for a narrow definition, where trade is a broader category and markets are a special case, involving organized and recurrent exchanges. Nevertheless, it is possible to make progress with a broader definition alongside the narrower one, as long as the chosen meaning is made clear and explicit.

The third case involves the definition of the term institution. Unlike many other terms in the social sciences, there is a near-consensus on a taxonomic definition in this instance. But some confusions and important disagreements on ontological issues remain (Epstein, 2015; Guala, 2016; Miller, 2010). Nevertheless, there has been sufficient taxonomic consensus over the object of analysis to enable considerable advance. This in turn may open up a vista of more extensive and well-grounded empirical enquiry, spanning multiple academic disciplines.

\section{References}

Abercrombie, N., S. Hill and B. S. Turner (2000), The Penguin Dictionary of Sociology (4th edn), London: Penguin.

Alchian, A. A. and H. Demsetz (1972), "Production, Information Costs, and Economic Organization," American Economic Review, 62: 777-795.

Aoki, M. (2001) Toward a Comparative Institutional Analysis, Cambridge, MA: MIT Press.

Aristotle, (1853), The Organon, or Logical Treatises of Aristotle, translated and introduced by Octavius Freire Owen, 2 vols, London: Bohn.

Aristotle, (1901), Aristotle's Posterior Analytics, translated E. S. Bouchier, Oxford: Blackwell.

Aristotle, (1956), Metaphysics, edited and translated by John Warrington with an introduction by W. D. Ross, London: Dent.

Baker, W. E. (1984), “The Social Structure of a National Securities Market,” American Journal of Sociology, 89: 775-811.

Belnap, N. D. (1993), On Rigorous Definitions, Philosophical Studies, 72: 115-146.

Bhaskar, R. (1975), A Realist Theory of Science. Leeds: Leeds Books.

Binmore, K. (1994), Playing Fair: Game Theory and the Social Contract. Volume I, Cambridge, MA: MIT Press.

Binmore, K. (1998), Just Playing: Game Theory and the Social Contract. Volume 2, Cambridge, MA: MIT Press.

Block, F. (1990), Postindustrial Possibilities: A Critique of Economic Discourse, Berkeley: University of California Press.

Bowker, G. C. and S. L. Star (1999), Sorting Things Out: Classification and Its Consequences, Cambridge, MA: MIT Press.

Boyd, R. (1991), "Realism, Anti-Foundationalism, and the Enthusiasm for Natural Kinds," Philosophical Studies, 61: 127-148.

Carter, R. and G. M. Hodgson (2006), "The Impact of Empirical Tests of Transaction Cost Economics on the Debate on the Nature of the Firm," Strategic Management Journal, 27: 461-476. 
Cheung, S. N. S. (1983), "The Contractual Nature of the Firm," Journal of Law and Economics, 26: 1-21.

Cliff, T. (1955), Stalinist Russia: A Marxist Analysis, London: Michael Kidron.

Coase, R. H. (1937), "The Nature of the Firm," Economica, 4, New Series, 386-405.

Coase, R. H. (1974), “The Market for Goods and the Market for Ideas,” American Economic Review (Papers and Proceedings), 64: 384-391.

Coase, R. H. and N. Wang (2012), How China Became Capitalist, London and New York: Palgrave Macmillan.

Commons, J. R. (1934), Institutional Economics - Its Place in Political Economy, New York: Macmillan.

Cook, R. T. (2009), "Intensional Definition," in R. T. Cook (2009), A Dictionary of Philosophical Logic, Edinburgh: Edinburgh University Press, p. 155.

Crawford, S. E. S. and E. Ostrom (1995), “A Grammar of Institutions,” American Political Science Review 89: 582-600.

De Queiroz, K. (1994), "Replacement of an Essentialistic Perspective on Taxonomic Definitions as Exemplified by the Definition of 'Mammalia'," Systematic Biology, 43: 497-510.

De Queiroz, K. (2005), “Ernst Mayr and the Modern Concept of Species,” Proceedings of the National Academy of Sciences, 102 (supplement), 6600-6607.

Deakin, S., D. Gindis, G. M. Hodgson, Huang, K. and Pistor, K. (2017), "Legal Institutionalism: Capitalism and the Constitutive Role of Law," Journal of Comparative Economics, 45: 188-200.

Demoss, D. and Devereux, D. (1988), "Essence, Existence, and Nominal Definition in Aristotle's "Posterior Analytics" II 8-10', Phronesis, 33: 133-154.

Director, A. (1964), "The Parity of the Economic Market Place," Journal of Law and Economics, 7: 1-10.

Dore, R. (1983), "Goodwill and the Spirit of Market Capitalism,” British Journal of Sociology, 34: 459-482.

Douglas, M. T. (1986), How Institutions Think (London and Syracuse: Routledge \& Kegan Paul and Syracuse University Press).

Durlauf, S. N. and L. E. Blume (eds) (2008), The New Palgrave Dictionary of Economics, 2nd edition, London and New York: Palgrave.

Eggertsson, T. (1990), Economic Behavior and Institutions, Cambridge: Cambridge University Press.

Epstein, B. (2015), The Ant Trap: Rebuilding the Foundations of the Social Sciences, Oxford and New York: Oxford University Press.

EU Council (2008), "EU Council Regulation (EC) No 479/2008 of 29 April 2008, Annex IV,” Official Journal of the European Union. Available at http://eur-lex.europa.eu/ LexUriServ/LexUriServ.do? uri=OJ:L:2008:148:0001:0061:en:PDF (accessed 13 May 2018).

Fama, E. F. (1980), “Agency Problems and the Theory of the Firm," Journal of Political Economy, 88: 288-307.

Fodor, J. A. (1998), Concepts: Where Cognitive Science Went Wrong, Oxford and New York: Oxford University Press.

Fodor, J. A., M. F. Garrett, E. C. T. Walker and C. H. Parkes (1980), “Against Definitions,” Cognition, 8: 263-267. 
Frege, G. (1914), "Logic in Mathematics," in H. Hermes, F. Kambartel, and F. Kaulbach (eds) (1979), Gottlob Frege: Posthumous Writings, Chicago: University of Chicago Press, pp. 203-250.

Frigg, R. and Nguyen, J. (2017), “Models and Representation' in L. Magnani and T. Bertolotti (eds) Springer Handbook of Model-Based Science, Berlin: Springer, pp. 49-102.

Giddens, A. (1984), The Constitution of Society: Outline of the Theory of Structuration, Cambridge: Polity Press.

Gindis, D. (2009), "From Fictions and Aggregates to Real Entities in the Theory of the Firm," Journal of Institutional Economics, 5: 25-46.

Gindis, D. (2016), "Legal Personhood and the Firm: Avoiding Anthropomorphism and Equivocation," Journal of Institutional Economics, 12: 499-513.

Godfrey-Smith, P. (2009), Darwinian Populations and Natural Selection, Oxford: Oxford University Press.

Goldberg, V. P. (1980), "Relational Exchange: Economics and Complex Contracts," American Behavioral Scientist, 23: 337-352.

Grayling, A. C. (1988), Wittgenstein, Oxford: Oxford University Press.

Guala, F. (2016), Understanding Institutions: The Science and Philosophy of Living Together, Princeton, NJ: Princeton University Press.

Hacking, I. (1983), Representing and Intervening: Introductory Topics in the Philosophy of Science, Cambridge: Cambridge University Press.

Hacking, I. (1995), “The Looping Effect of Human Kinds,” in D. Sperber, D. Premack and A. J. Premack (eds) (1995), Causal Cognition: A Multidisciplinary Debate, Oxford: Clarendon Press, pp. 351-383.

Hacking, I. (1999), The Social Construction of What? Cambridge, MA: Harvard University Press.

Hacking, I. (2007), "Kinds of People: Rosy Dawn, Scholastic Twilight," Royal Institute of Philosophy Supplement, 61: 203-239.

Hall, P. A. and Soskice, D. (eds) (2001), Varieties of Capitalism: The Institutional Foundations of Comparative Advantage, Oxford: Oxford University Press.

Harari, O. (2005), Knowledge and Demonstration: Aristotle's Posterior Analytics, London and New York: Springer.

Härdle, W. K. and A. P. Kirman (1995), "Nonclassical Demand: A Model-Free Examination of Price Quantity Relations in the Marseille Fish Market," Journal of Econometrics, 67: 227-257.

Harré, R. and E. H. Madden (1975), Causal Powers: A Theory of Natural Necessity, Oxford: Basil Blackwell.

Hart, O. D. and Moore, J. H. (1990), "Property Rights and the Nature of the Firm," Journal of Political Economy, 98: 1119-11158.

Hempel, C. G. (1952), Fundamentals of Concept Formation in Empirical Science, Chicago: Chicago University Press.

Hindess, B. (1977), Philosophy and Methodology in the Social Sciences, Brighton: Harvester.

Hindriks, F. and F. Guala (2015), "Institutions, Rules, and Equilibria: A Unified Theory," Journal of Institutional Economics, 11: 459-480.

Hobbes, T. (1651), Leviathan or The Matter, Forme and Power of a Common Wealth Ecclesiasticall and Civil, London: Andrew Crooke.

Hodgson, G. M. (2001), How Economics Forgot History: The Problem of Historical Specificity in Social Science, London and New York: Routledge.

Hodgson, G. M. (2006), “What Are Institutions?” Journal of Economic Issues, 40: 1-25. 
Hodgson, G. M. (2014), "What is Capital? Economists and Sociologists have changed its Meaning - Should it be Changed Back?" Cambridge Journal of Economics, 38: 10631086.

Hodgson, G. M. (2015a), Conceptualizing Capitalism: Institutions, Evolution, Future, Chicago: University of Chicago Press.

Hodgson, G. M. (2015b), “On Defining Institutions: Rules versus Equilibria,” Journal of Institutional Economics, 11: 499-505.

Hodgson, G. M. (2016), "Varieties of Capitalism: Some Philosophical and Historical Considerations," Cambridge Journal of Economics, 40: 941-960.

Hyde, D. (2008), Vagueness, Logic and Ontology, Aldershot: Ashgate.

Jary, D. and J. Jary (eds) (1991), The Harper Collins Dictionary of Sociology, New York: Harper Collins.

Jensen, M. C. and Meckling, W. H. (1976), “Theory of the Firm: Managerial Behavior, Agency Costs and Ownership Structure," Journal of Financial Economics, 3: 305-360.

Kemp, T. S. (2005), The Origin and Evolution of Mammals, Oxford and New York: Oxford University Press.

Kitcher, P. (1993), The Advancement of Science: Science without Legend, Objectivity without Illusions, Oxford and New York: Oxford University Press.

Kitcher, P. (2012), Preludes to Pragmatism: Towards a Reconstruction of Philosophy, Oxford and New York: Oxford University Press.

Klaes, M. (2004), “Evolutionary Economics: In Defence of 'Vagueness', Journal of Economic Methodology, 11: 359-376.

Klaes, M. (2006), "Founding Economic Concepts," Storio del Pensiero Economico, new series, 3: 21-37.

Knight, J. (1992), Institutions and Social Conflict, Cambridge: Cambridge University Press.

Langlois, R. N. (1995), "Capabilities and Coherence in Firms and Markets," in C. A. Montgomery (ed.) (1995), Resource-Based and Evolutionary Theories of the Firm: Towards a Synthesis, Boston: Kluwer, pp. 71-100.

Lawson, T. (1997), Economics and Reality, London and New York: Routledge.

Lewis, D. (1969), Convention: A Philosophical Study, Cambridge, MA: Harvard University Press

Locke, J. (1690), An Essay Concerning Human Understanding, London: Basset.

Machlup, F. (1963), Essays in Economic Semantics, Englewood Cliffs, NJ: Prentice-Hall.

Machlup, F. (1967), "Theories of the Firm: Marginalist, Behavioral, Managerial," American Economic Review, 57: 1-33.

Machlup, F. (1978), Methodology of Economics and Other Social Sciences, London: Academic Press.

Magnus, P. D. (2015), “John Stuart Mill on Taxonomy and Natural Kinds," HOPOS: Journal of the International Society for the History and Philosophy of Science, 5: 269-280.

Malthus, T. R. (1827), Definitions in Political Economy, London: John Murray.

Mantzavinos, C. (2001), Individuals, Institutions, and Markets, Cambridge and New York: Cambridge University Press.

Mantzavinos, C. (2006), “The Role of Definitions in Institutional Analysis," Wettbewerb und Gesundheitswesen: Konzeptionen und Felder ordnungsökonomischen Denkens, Schriftenreihe Adrássy Universität, Band 4, Budapest, pp. 85-92.

Marshall, A. (1920), Principles of Economics: An Introductory Volume (8th edn), London: Macmillan. 
Marshall, G. (ed.) (1998), Oxford Dictionary of Sociology, Oxford and New York: Oxford University Press.

Mayr, E. (1972), “The Nature of the Darwinian Revolution,” Science, 176: 981-989.

Mayr, E. (1982), The Growth of Biological Thought: Diversity, Evolution, and Inheritance, Cambridge, MA: Harvard University Press

McCloskey, Deirdre N. (2010), Bourgeois Dignity: Why Economics Can't Explain the Modern World, Chicago: University of Chicago Press.

McCloskey, Donald N. (1985), The Rhetoric of Economics, Madison, WI: University of Wisconsin Press.

McMillan, J. (2002), Reinventing the Bazaar: A Natural History of Markets, New York and London: Norton.

Mill, J. S. (1843), A System of Logic: Ratiocinative and Inductive, Being a Connected View of the Principles of Evidence and the Methods of Scientific Investigation, 2 vols (1st edn), London: Longman, Green, Reader and Dyer.

Miller, S. (2010), The Moral Foundations of Social Institutions: A Philosophical Study, Cambridge and New York: Cambridge University Press.

Mirowski, P. (2007), "Markets Come to Bits: Evolution, Computation and Markomata in Economic Science," Journal of Economic Behavior and Organization, 63: 209-242.

Mises, L. von (1949), Human Action: A Treatise on Economics (1st edn), London and New Haven: William Hodge and Yale University Press.

Morgan, M. S. (2012), The World in a Model: How Economists Work and Think, Cambridge and New York: Cambridge University Press.

Nelson, R. R. (1991), "Why Do Firms Differ, and How Does it Matter?" Strategic Management Journal, 12, Special Issue, 61-74.

North, D. C. (1990), Institutions, Institutional Change and Economic Performance, Cambridge and New York: Cambridge University Press.

North, D. C. (1994), "Economic Performance through Time," American Economic Review, 84: 359-367.

North, D. C., J. J. Wallis and B. R. Weingast (2009), Violence and Social Orders: A Conceptual Framework for Interpreting Recorded Human History, Cambridge and New York: Cambridge University Press.

O’Neill, J. (1998), The Market: Ethics, Knowledge and Politics, London and New York: Routledge.

Ostrom, E. (1990), Governing the Commons: The Evolution of Institutions for Collective Action, Cambridge: Cambridge University Press.

Outhwaite, W. and T. Bottomore (1994), The Blackwell Dictionary of Twentieth Century Thought, Oxford: Blackwell.

Parsons, T. (1983), On Institutions and Social Evolution: Selected Writings, with an introduction by Leon H. Mayhew, Chicago: University of Chicago Press.

Popper, K. R. (1990), A World of Propensities, Bristol: Thoemmes.

Porpora, D. V. (1987), The Concept of Social Structure, New York and London: Greenwood Press.

Quine, W. v. O. (1960), Word and Object, Cambridge, MA: Harvard University Press.

Rasmussen, D. B. (1984), "Quine and Aristotelian Essentialism,” The New Scholasticism, 58 : 316-335.

Richardson, G. B. (1972), “The Organisation of Industry,” Economic Journal, 82: 883-896.

Robinson, R. (1950), Definition, Oxford: Clarendon Press. 
Rosenbaum, E. F. (2000), "What is a Market? On the Methodology of a Contested Concept," Review of Social Economy, 58: 455-482.

Rowe, N. (1989), Rules and Institutions, London: Philip Allan.

Runciman, W. G. (1983), “Capitalism without Classes: The Case of Classical Rome,” British Journal of Sociology 34: 157-181.

Russell, B. (1923), "Vagueness," Australasian Journal of Psychology and Philosophy, 1: 8492.

Scott, W. R. (1995), Institutions and Organizations, Thousand Oaks, CA and London: Sage.

Searle, J. R. (1995), The Construction of Social Reality, London: Allen Lane.

Searle, J. R. (2005), “What is an Institution?' Journal of Institutional Economics, 1, 1-22.

Schotter, A. R. (1981), The Economic Theory of Social Institutions, Cambridge: Cambridge University Press.

Sober, E. (1980), "Evolution, Population Thinking and Essentialism," Philosophy of Science, 47: 350-383.

Thomasson, A. L. (2003), "Realism and Human Kinds," Philosophy and Phenomenological Research, 67: 580-609.

Weber, M. (1949), Max Weber on the Methodology of the Social Sciences, Glencoe, IL: Free Press.

Whitehead, A. N. (1929), Process and Reality: An Essay in Cosmology, Cambridge: Cambridge University Press.

Williams, R. (1976), Keywords: A Vocabulary of Culture and Society, Glasgow: Fontana.

Williamson, O. E. (1975), Markets and Hierarchies: Analysis and Anti-Trust Implications: A Study in the Economics of Internal Organization, New York: Free Press.

Williamson, O. E. (1991), "Comparative Economic Organization: The Analysis of Discrete Structural Alternatives,” Administrative Science Quarterly, 36: 269-296.

Wittgenstein, L. (1958), Philosophical Investigations (2nd edn), Oxford: Basil Blackwell.

Zadeh., L. A. (1996), "Fuzzy Logic = Computing with Words," IEEE Transactions on Fuzzy Systems, 4: 103-111.

Cite this article: Hodgson GM (2018). Taxonomic definitions in social science, with firms, markets and institutions as case studies. Journal of Institutional Economics 0, 1-18. https://doi.org/10.1017/ S1744137418000334 